\title{
RODOVIAS NA AMAZÔNIA LEGAL E OS ÓBITOS CAUSADOS POR ACIDENTES DE TRANSPORTE TERRESTRE ${ }^{1}$
}

\author{
Isabela Soares Colares ${ }^{2}$ \\ Geraldo Alves de Souza ${ }^{3}$
}

\begin{abstract}
O aumento da taxa de motorização se caracteriza como uma das principais causas de crescimento dos acidentes de transporte terrestre no Brasil. Reconhece-se este como um fator importante, porém, ao contrário do restante do país, a Amazônia Legal apresenta uma configuração geográfica com padrões de cidades cuja gênese ocorreu inicialmente às margens dos rios e mais recentemente, por meio de rodovias. Dessa forma, o objetivo desse artigo é analisar a relação entre os diferentes tipos de acesso às sedes municipais, a população, a frota de veículos e o acumulado de ocorrências de óbitos por acidentes de transporte terrestre no período de 2009 a 2013 nos municípios dos estados do Amazonas, Rondônia e Pará. Conclui-se que mesmo que o aumento da população e da frota de veículos reflitam para a geração de vítimas nos municípios, há aqueles que se destacam com maior número por ter influência de rodovias no seu território.
\end{abstract}

Palavras-chave: estradas, municípios, transporte, mortalidade.

\section{HIGHWAYS IN LEGAL AMAZON AND THE DEATHS CAUSED BY LAND TRANSPORT ACCIDENTS}

The enhancement of the motorization rate is one of the main causes of land transport accident growth in Brazil. This is recognized as an important factor but unlike the rest of the country, the Legal Amazon presents a geographical configuration with city criteria whose inception occurred initially at the riverbanks and newly through highways. $\mathrm{n}$ this way, the focus of this article is to analyze: the relationship between different types of access to municipal headquarters, population, vehicle fleet and the accumulated occurrence of deaths from land transport accidents from 2009 to 2013 in the municipalities of the states Amazonas, Rondônia, and Pará. It is concluded that even though the increase in population and fleet of vehicles reflects the generation of victims in the municipalities, some stand out with greater influence by having highways in their territory.

Keywords: highways, municipalities, transportation, mortality.

\footnotetext{
1 Este artigo é parte dos resultados da dissertação de Mestrado desenvolvida no programa de Pós-Graduação em Geografia da Universidade Federal do Amazonas, intitulada "A geografia dos óbitos causados por transporte terrestre na Amazônia Legal: uma análise do período de 2009 a 2013".

2 Universidade Federal do Amazonas - isabela.colares@hotmail.com

3 Universidade Federal do Amazonas - geraldoalves@ufam.edu.br
} 


\section{INTRODUÇÃO}

Considera-se como acidente de trânsito um evento envolvendo um ou mais veículos, motorizados ou não, em movimento por uma via, o qual provoca ferimentos nas pessoas ou danos físicos em veículos ou objetos de outra natureza (postes, sinal de trânsito etc.) (FERRAZ et al., 2008). Para Vasconcellos (2012), os acidentes de trânsito constituem-se como problemas tanto nos países desenvolvidos quanto nos em desenvolvimento, embora com características diferentes em cada nação ou região do mundo.

Dentre os fatores apontados como causa estão: ausência de leis adequadas e de fiscalização; falta de atenção ou de respeitos aos demais usuários da via púbica (DA MATTA et al., 2010); uso de álcool por motoristas, bem como a adoção de comportamentos de risco no trânsito (ANDRADE et al., 2003; WILDE, 2005); e condições de pavimento, fluxo de veículos e de pedestres, sinalização, velocidade e visibilidade, entre outros (CARDOSO \& GOLDNER, 2007). Trindade Junior \& Nassi (2005) assinalam a relação entre acidentes e miséria da população, constatando que as capitais brasileiras que apresentaram elevados índices de miséria são justamente aquelas com as mais altas taxas de fatalidade no trânsito, já que renda e mobilidade caminham juntas (TRINDADE JUNIOR \& NASSI, 2005).

De acordo com Morais Neto et al. (2014) este é resultado de diferentes causas, tais como o expressivo aumento do número de veículos circulantes. Já Mortarie e Euzébio (2009) os associam ao crescimento acelerado e desordenado dos centros urbanos, à escassez da infraestrutura urbana, à atuação tardia da educação para o trânsito, à fragilidade da legislação com fiscalização deficiente e à alta frequência de comportamentos inadequados.

Na Amazônia Legal, a dinâmica populacional, especialmente, a partir de meados da década de 1960, mostrou-se muito intensa, expressão dos efeitos dos investimentos públicos na época do Regime Militar. Hoje, a região da Amazônia Legal conta com proximamente 25 milhões de habitantes, cerca de 13,4\% do Brasil. A maioria dos habitantes da Amazônia é urbana, com grau de urbanização de 73,5\% em 2010. Assim, a Amazônia tornou-se uma fronteira agrícola urbanizada, uma "floresta urbanizada" (SAWYER, 1987; BECKER, 1995; BROWDER e GODFREY, 1997; CASTRO, 2008).

No que se trata dos dados de motorização o Departamento Nacional de Trânsito apontam que a frota circulante da Amazônia Legal mais que dobrou no período de 2001 a 2015, passando de 3,5 para 8 milhões de veículos, um aumento de mais de $228 \%$ no período. Os veículos de duas rodas de 500 mil em 2001 subiu para 4 milhões em 2015, representando uma taxa de crescimento de $800 \%$ no período, passando a ser superior à dos automóveis em 2009. Considerando os dados, infere-se que há um contexto de causalidade para o aumento das estatísticas de óbitos. Porém a Amazônia Legal apresenta singularidades de acesso e formação das cidades, dadas aos meios de transporte rodoviário e fluvial: se por um lado a Amazônia Ocidental apresenta forte influência fluvial na ocupação e surgimento das cidades, na Amazônia Oriental muitas cidades foram erguidas às margens de rodovias (Maranhão, Tocantins, Mato Grosso e parte do estado do Pará).

Estudos sobre a Amazônia demonstram haver grandes diferenças entre os estados que a compõe. Becker (2005) reconhece uma nova geografia da Amazônia, baseada na heterogeneidade de três macrorregiões: a primeira é chamada de "arco do fogo" e que a autora denomina de "arco do povoamento consolidado", porque é onde estão os municípios com maiores índices de densidade demográfica, as estradas, e o cerne da economia; a outra macrorregião da Amazônia central corresponde ao restante do estado do Pará, que é a porção mais vulnerável da Amazônia, por ter maior influência de importantes eixos 
rodoviários, a última é a Amazônia Ocidental, que tem a maior área de fronteira política e é a mais preservada, e seu povoamento foi pontual, decorrente da Zona Franca de Manaus.

Este regionalismo está relacionado com os diferentes processos de ocupação que sucedeu sobre a região. No início da década de 1960, as políticas desenvolvimentistas voltadas para a integração nacional da Amazônia resultaram no aumento do fluxo migratório para região que se concentrou na área de influência de rodovias, tais como: a BR-364 (municípios de Rondônia e noroeste de Mato Grosso), BR-163, (norte de Mato Grosso e sudoeste do Pará), próximos aos eixos da PA-150 e MT-158 no sudeste do Pará e leste de Mato Grosso e ao longo do eixo da BR-174 em Roraima. Por outro lado, há aqueles municípios que se formaram às margens de rios e áreas litorâneas da região, como grande parte dos municípios do estado do Amazonas, oeste do Acre, região do baixo Amazonas no Pará, e litoral do Pará e Maranhão (NASCIMENTO \& SILVA, 2007). Destes, alguns não possuem acesso às sedes municipais por rodovias; apenas por vias fluviais.

Considerando este contexto, entende-se que essas diferenças da geografia do transporte da região devem ser consideradas ao analisar os óbitos causados por acidentes de transporte terrestres na Amazônia, especificamente naqueles estados cuja implantação das rodovias possibilitou a novas configurações espaciais. Pois estes podem divergir ou convergir do que se toma como pressuposto da explicação das principais causas dos óbitos a nível nacional, que toma como principal causa o aumento da população nos centros urbanos e da frota de veículos motorizado. Nesse sentido, a hipótese deste trabalho é, que os municípios com acesso por rodovias (asfaltadas e não asfaltadas) possuem maior quantidade de veículos por habitante e apresentam maior quantidade de óbitos causados por acidentes de transporte terrestres que aqueles com acesso apenas por via fluvial. E tem como objetivo analisar a relação entre os diferentes tipos de acesso às sedes municipais, a população, a frota de veículos e o acumulado de ocorrências de óbitos por acidentes de transporte terrestre no período de 2009 a 2013 nos municípios dos estados do Amazonas, Rondônia, e Pará buscando identificar possíveis variações das ocorrências de óbitos em função dessas variáveis.

\section{PROCEDIMENTOS METODOLÓGICOS}

\section{CARACTERIZAÇÃO DA ÁREA DE ESTUDO}

Este artigo é um produto de uma dissertação de mestrado que apresenta uma análise sucinta dos óbitos na Amazônia Legal, e sua correlação com as variáveis de população, frota de veículos e os tipos de acesso às sedes municipais. Porém, em razão dos resultados assemelharem-se comprovando a hipótese da pesquisa, neste artigo optouse por apresentar apenas três estados - o Amazonas, Rondônia e o Pará.

As justificativas da escolha dos respectivos estados dar-se-ão pelas suas configurações quanto a sua geografia do transporte e ocupação do território. O processo de ocupação de Rondônia e no Pará teve início a partir dos rios navegáveis da região. Posteriormente, com o processo de colonização que estimulou a migração da população de outras regiões do país, estradas passaram a ser abertas, facilitando a ocupação, principalmente às margens da BR-364 e da Belém-Brasília.

A BR-364 corta o estado de Rondônia de um extremo a outro e permite o acesso às cidades como Vilhena, Pimenta Bueno, Cacoal, Presidente Médici, Ji-Paraná, Ouro Preto do Oeste, Jaru, Ariquemes, Itapuã do Oeste, Candeias do Jamari e Porto Velho, este já é localizado às margens do rio Madeira. A BR-429 possibilita a conexão de territórios mais 
distantes e menos povoados da região, com eixo de leste para oeste até as margens do rio Guaporé, no município de Costa Marques. A partir da BR-364 para o sul, a rodovia BR-425 possibilita o acesso às cidades localizadas às margens do rio Madeira e Mamoré. Outras dezenas de rodovias estaduais traçadas em formato quase simétricos possibilitam a integração do território rondoniense.

O Pará é banhado ao norte pelo rio Amazonas, e a partir dele importantes rios da bacia Amazônica fazem a conexão de diversas cidades; muitas delas já acessadas por rodovias. Importantes eixos rodoviários federais cortam o estado estabelecendo a ligação deste com o restante do Brasil. No sentido norte-sul as mais importantes são: BRs-158 e a 153 (denominada de BR-010) que corta o leste do estado, estabelecendo a conexão de Belém com diversos municípios do oeste do Maranhão, Tocantins, Mato Grosso e o restante do Brasil. Na região oeste do estado, a partir de Santarém (margem direita do rio Amazonas) a BR-163 segue para o sul até o entroncamento com a BR-364 no Mato Grosso. No sentido horizontal, a BR-230 corta o estado de leste a oeste e conecta este ao Maranhão e Amazonas. Como a maior parte do seu eixo não é pavimentada no estado, os municípios da região mais central e oeste do estado têm acesso precário.

Já no Amazonas, o povoamento ocorreu sobremaneira por intermédio dos rios navegáveis da bacia hidrográfica Amazônica. Dessa forma, a maior parte das sedes situamse às margens dos principais rios da região. Existem poucas rodovias no território amazonense. Até mesmo aqueles municípios que apresentam acesso por rodovias têm um sistema de transporte rodofluvial, tanto os rios quanto as rodovias conectam a sede municipal. A maior concentração viária ocorre nos municípios próximos à capital, no sul e sudeste do estado. Dentre as rodovias federais que cortam o estado, a BR-174 é a única que apresenta boas condições de tráfego. Ela conecta Manaus ao município de Presidente Figueiredo e ao norte segue até a Venezuela. No sul, a partir da margem direita do rio Solimões, com nomenclatura de BR-319, ela conecta Manaus a Humaitá, com a maior parte do trecho sem pavimentação. Ainda no sul do estado, a BR-230 conecta os municípios de Lábrea, Humaitá e Apuí e segue em direção ao Pará.

Os procedimentos metodológicos adotados na pesquisa estão apresentados no fluxograma da figura 1, e especificados a seguir:

Figura 1 - Fluxograma dos Procedimentos Metodológicos

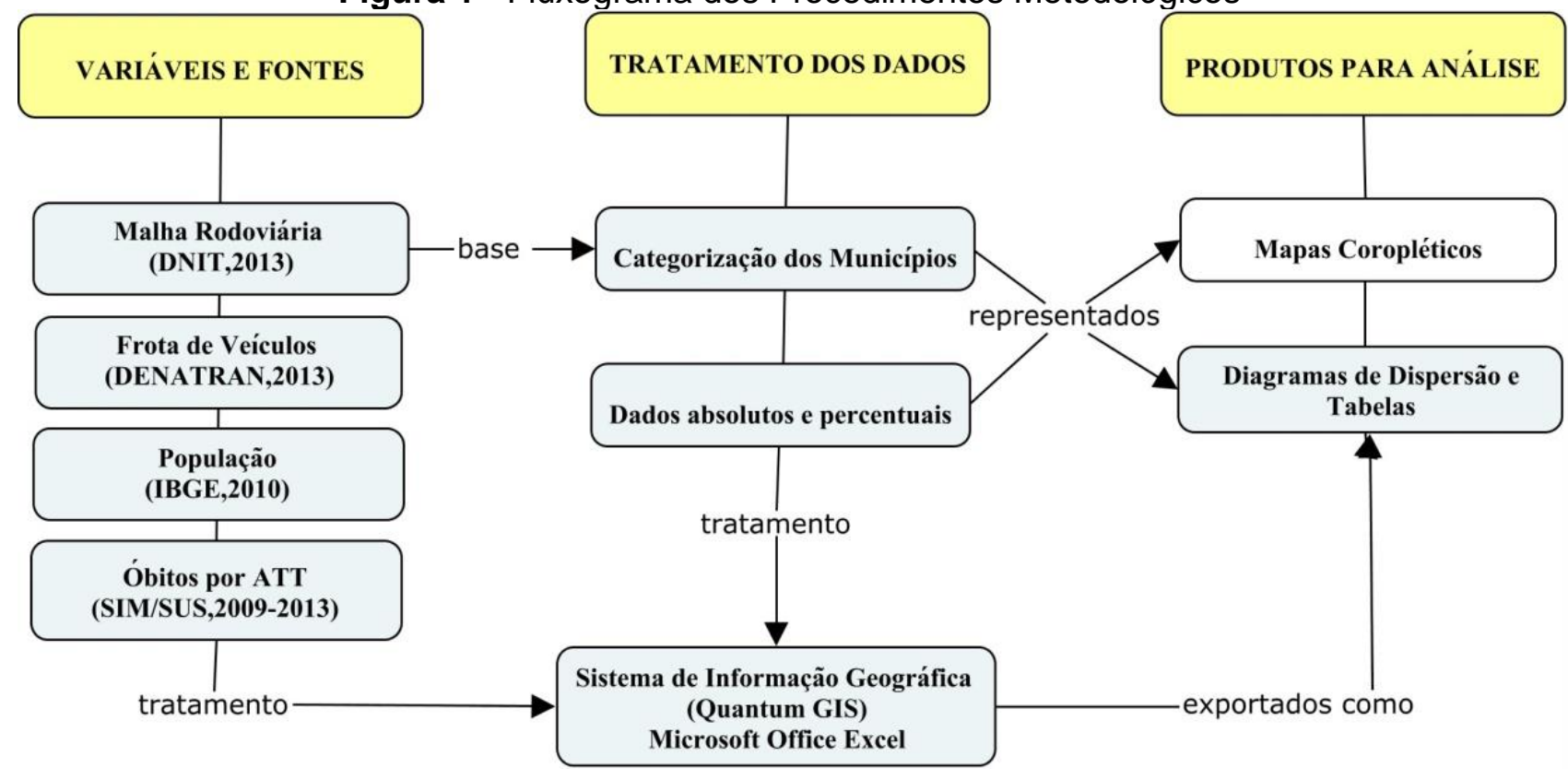

Estudos Geográficos, Rio Claro. 2020, 18, e15309 (ISSN 1678-698X)

http://www.periodicos.rc.biblioteca.unesp.br/index.php/estgeo 


\section{FONTES E VARIÁVEIS DE DADOS}

Os dados de óbitos usados neste artigo são da Base Nacional do Sistema de Informações sobre Mortalidade SIM disponibilizados por meio do Departamento de Informática do Sistema Único de Saúde (DATASUS) que compila as estatísticas de acidentes de trânsito a partir da documentação das pessoas atendidas no SUS. As informações do sistema são originadas do preenchimento e coleta da Declaração de Óbitos - DO feita nos estabelecimentos de saúde.

As outras variáveis utilizadas são: dados do último censo demográfico municipal de 2010 do IBGE; dados da frota de veículos do Registro Nacional de Veículos Automotores (RENAVAM) do Departamento Nacional de Trânsito -DENATRAN, para o ano de 2013; dados geoespaciais referentes à malha municipal digital, com os municípios que compõe os estados, produzida em 2010 em formato shapefile disponibilizada pelo IBGE; mapas digitais e dados vetoriais da malha viária, contendo estradas estaduais e federais, disponibilizada pelo DNIT e publicada no ano de 2013.

\section{MANIPULAÇÃO E TRATAMENTO}

Os dados do DNIT foram utilizados para realizar a classificação de acesso às sedes municipais dos estados. O primeiro critério usado na categorização foi à inspeção visual dos mapas digitais em função dos tipos de acesso (fluvial e/ou rodoviário). Como um desdobramento da primeira classificação, a segunda inclui as especificidades dos municípios que apresentam conexão por rodovias. Nesta classificação, fez-se o uso da base de dados vetorial das sedes municipais do IBGE e a da rede rodoviária federal, estadual (pavimentadas e não pavimentadas) do DNIT, carregadas no ambiente do QGIS com o OpenLayers do Google Maps. A partir desses dados, foi possível fazer uma divisão dos diferentes acessos rodoviários, conferindo a partir das imagens de satélite os trechos pavimentados e não pavimentados e a localização mais precisa da sede municipal, comparando-os com a base cartográfica. Dessas classificações, obtivemos quatro grupos de municípios, a saber: rodovias federais pavimentadas (totalmente conectados), rodovias estaduais pavimentadas (medianamente conectados), rodovias não pavimentadas (precariamente conectados), e os sem conexão rodoviária.

Para as demais variáveis optou-se por trabalhar em números absolutos e percentuais, organizados em planilhas Excel. Após tratados e preparados, os dados foram carregados no ambiente do Sistema de Informação Geográfica de software QGIS, para realização da união da tabela, com a base cartográfica da divisão municipal. Destes procedimentos, obteve os seguintes produtos: a) mapas coropléticos, que é uma forma de demonstração dos dados agregados por área, um meio de rápida tradução dessas informações, com o uso da variável visual valor, variando a tonalidade do claro (pouca ocorrência) ao escuro (muitas ocorrências); b) tabela e diagramas de dispersão, em que os pontos no espaço cartesiano de $\mathrm{x}$ e y são usados para representar a distribuição das variáveis -população/óbitos e frota de veículos/óbitos. Como as capitais possuem uma participação da população, frota e óbitos muito superior aos demais municípios, influenciando na visualização e interpretação do comportamento destes no diagrama, optou-se por removê-las desta representação. 


\section{RESULTADOS E DISCUSSÕES}

\section{RONDÔNIA}

A figura 2, elaborada a partir da base do DNIT (2013), destaca que dos cinquenta e dois municípios de Rondônia, vinte sedes municipais têm acesso por rodovias federais (totalmente conectados), vinte e um por rodovias estaduais (medianamente conectado) e onze por rodovias não pavimentadas (precariamente conectado). Apesar de algumas cidades situarem-se na margem de rios como o Madeira, Guaporé e Mamoré, não há cidades com acesso exclusivamente por este modo. O mosaico de mapas da figura 2 ( $A$, $B, C$ e D) destaca a relação da população, frota de veículos e óbitos por ATT no estado. Visualmente os mapas apontam semelhança na distribuição espacial das variáveis.

Com uma população total de mais de 1.5 milhão de habitantes, o estado apresenta maior contingente populacional nos municípios onde a densidade de eixos rodoviários é mais elevada, conforme destaca a figura $2 \mathrm{~B}$. Os mais populosos são aqueles localizados na margem esquerda da rodovia BR-364 (sentido Porto Velho-Cuiabá), como Ji-Paraná, Ariquemes e Cacoal, que juntos concentram 18,2\% do total, entre 78.000 a 116.610 habitantes. No extremo norte, destaca-se com a maior população, a capital Porto Velho, com 428.527 habitantes, cerca de $27,4 \%$ do total. Já aqueles com menor população, a maioria localiza-se a oeste da rodovia BR-364. Destes, a menor participação percentual foi registrada por Castanheiras, Primavera de Rondônia, Rio Crespo, com aproximadamente 2.500 habitantes, Pimenteiras do Oeste, possui a menor população do estado, situada no sudoeste do estado, na fronteira com a Bolívia.

A distribuição espacial da frota de veículos ocorre de maneira bem similar àquela apresentada pela população, de acordo com a figura $2 \mathrm{C}$. Com 222.215 veículos, a capital concentra mais de $29 \%$ da frota. Ji-Paraná, a segunda maior do estado, com 9,5\%, mais de 72 mil veículos. Com percentual de aproximadamente 6,5\%, os municípios de Vilhena, Cacoal, Ariquemes, também concentram alta frota de veículos no estado, com mais de 45 mil veículos. Assim como apresentam a menor população, Primavera de Rondônia, Castanheiras, Rio Crespo, Pimenteiras do Oeste, também possuem a menor frota de veículos do estado. 
Figura 2 - Rondônia: Mosaico de mapas com as categorias de acesso (A), população (B), frota de veículos (C) e óbitos (D)

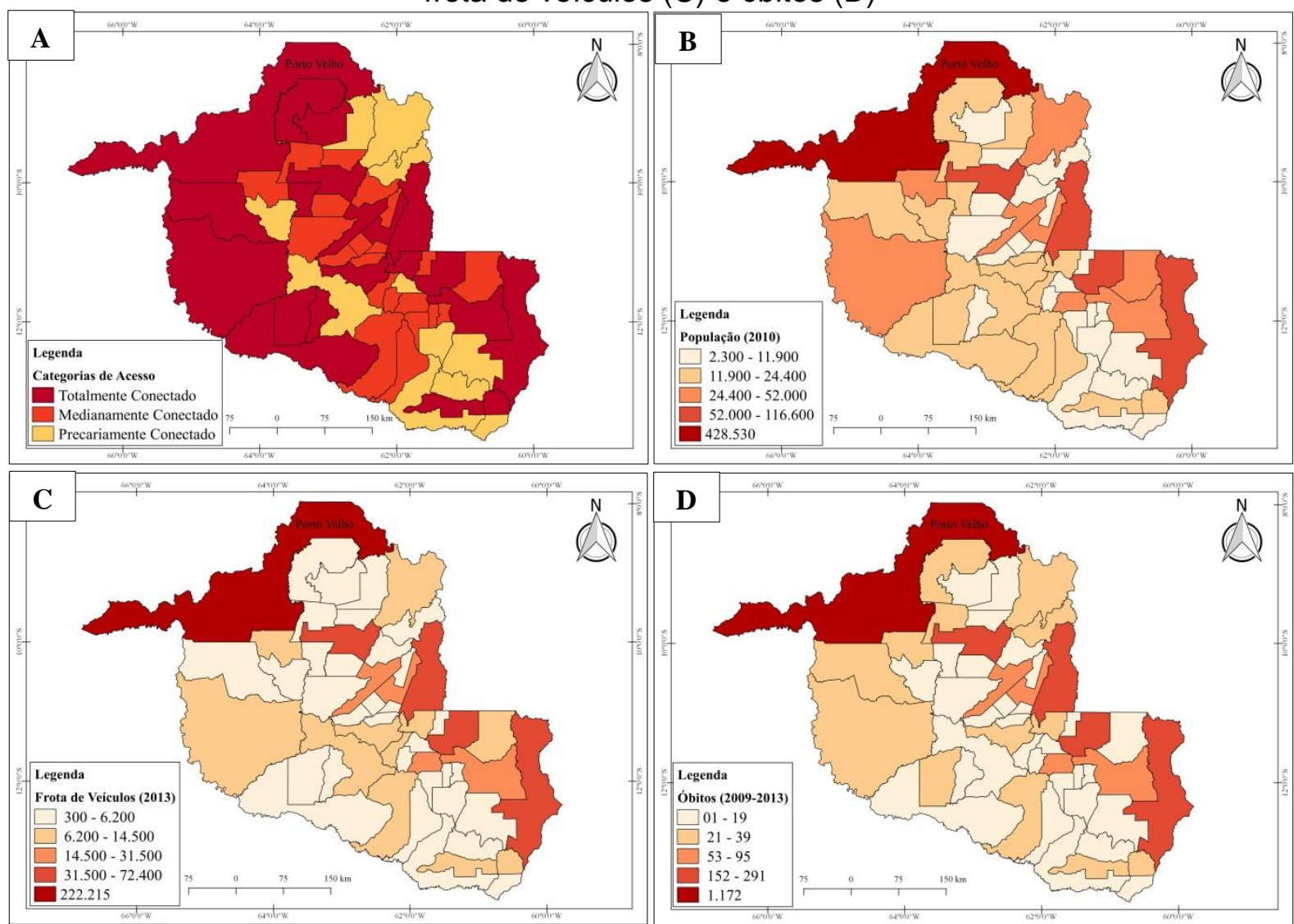

Fontes: DNIT, 2013; IBGE, 2010; DENATRAN, 2013; SIM/SUS, 2009-2013.

Com 2.903 óbitos no período de 2009 a 2013, dos nove estados, Rondônia é o único que teve ocorrência de óbitos por ATT em todos os municípios. A partir do mapa da figura $2 \mathrm{D}$, nota-se que há mais óbitos onde a população e a frota de veículos são mais altas, cujas sedes municipais são cortadas pela BR-364. No sentido Cuiabá-Porto Velho, os dados distribuem-se da seguinte maneira: Vilhena com 152, Cacoal, com 161, Ji-Paraná, com 291, segundo maior registro, e Ariquemes, com 210 óbitos. Porto Velho no nordeste do estado, com 1.172 mortes causadas por ATT no período da pesquisa, é o primeiro na geração de vítimas. Já aqueles com menor número de óbitos localizam-se, em sua grande maioria, na parte mais a oeste do estado.

Os diagramas de dispersão da figura 3 ( $\mathrm{A}$ e B) destacam a correlação das variáveis população e frota de veículos com os óbitos de cinquenta e um municípios de Rondônia, sem a capital, Porto Velho. 
Figura 3 - Rondônia: Diagramas de dispersão: (A) população municipal e (B) frota de veículos municipal; e óbitos por ATT

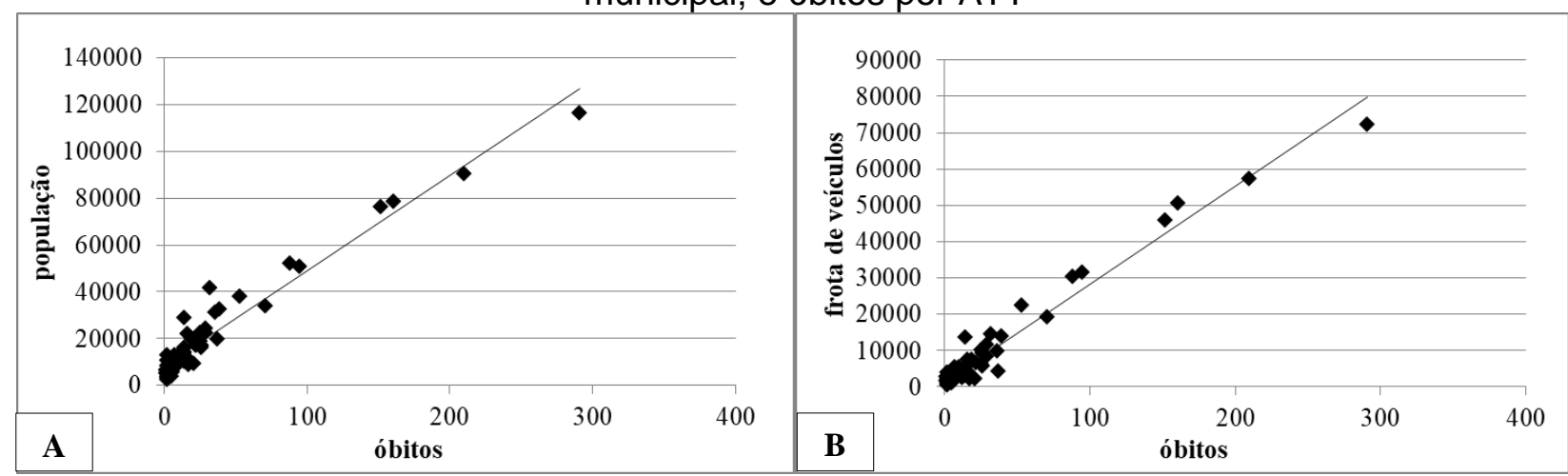

Fontes: IBGE, 2010; DENATRAN, 2013; SIM/SUS, 2009-2013.

Nota-se que nos dois gráficos, os pontos encontram-se perto da linha de tendência. A maior parte deles concentrados na base do diagrama, ressaltando municípios que registraram menos que 100 óbitos e outros mais dispersos. E no final da linha, o ponto mais isolado destaca a posição do município de Ji-Paraná, com quase 300 óbitos. Em ambos os gráficos, é nítido que há uma forte correlação das variáveis em Rondônia, ou seja: conforme cresce a população e a frota de veículos, cresce também o número de óbitos. Para melhor compreender esta relação, na tabela 1 são destacados, em ordem crescente, seis municípios de Rondônia que geraram maior quantidade de óbitos no período de 2009 a 2013, e comparados com população e a frota de veículos municipal.

Tabela 1- Rondônia: Representação em ordem crescente dos municípios com maior número de óbitos, comparados com a população e frota de veículos.

\begin{tabular}{l|r|r|r|r|r|r}
\hline \multirow{2}{*}{ Município } & \multicolumn{2}{|c|}{ Óbitos } & \multicolumn{2}{c|}{ População } & \multicolumn{2}{c}{ Frota de Veículos } \\
\cline { 2 - 7 } & Posição & \multicolumn{1}{c|}{ Total } & Posição & \multicolumn{1}{c}{ Total } & Posição & \multicolumn{1}{c}{ Total } \\
\hline Porto Velho & $1^{\circ}$ & 1.172 & 10 & 428.527 & $1^{\circ}$ & 222.215 \\
JiParaná & $2^{\circ}$ & 291 & 20 & 116.610 & $2^{\circ}$ & 72.319 \\
Ariquemes & $3^{\circ}$ & 210 & $3^{\circ}$ & 90.353 & $3^{\circ}$ & 57.322 \\
Cacoal & $4^{\circ}$ & 161 & 40 & 78.574 & $4^{\circ}$ & 50.644 \\
Vilhena & $5^{\circ}$ & 152 & $5^{\circ}$ & 76.202 & $5^{\circ}$ & 45.706 \\
Rolim de Moura & $6^{\circ}$ & 95 & $6^{\circ}$ & 50.648 & $7^{\circ}$ & 31.517 \\
\hline
\end{tabular}

Como é possível observar, há uma alta correlação da população, frota de veículos e óbitos no estado. Em cinco municípios, a posição é similar nas três variáveis, exceto para Rolim de Moura, que apresentou as sextas posições no número de óbitos e população e apresenta a sétima maior frota de veículos do estado. O mapa da figura 4 destaca doze municípios de Rondônia, com o menor e maior número de óbitos do estado, relacionados com tipo de acesso à sede municipal. 
Figura 4 - Rondônia: Mapa com o destaque dos municípios que geraram maior e menor número de óbitos por ATT

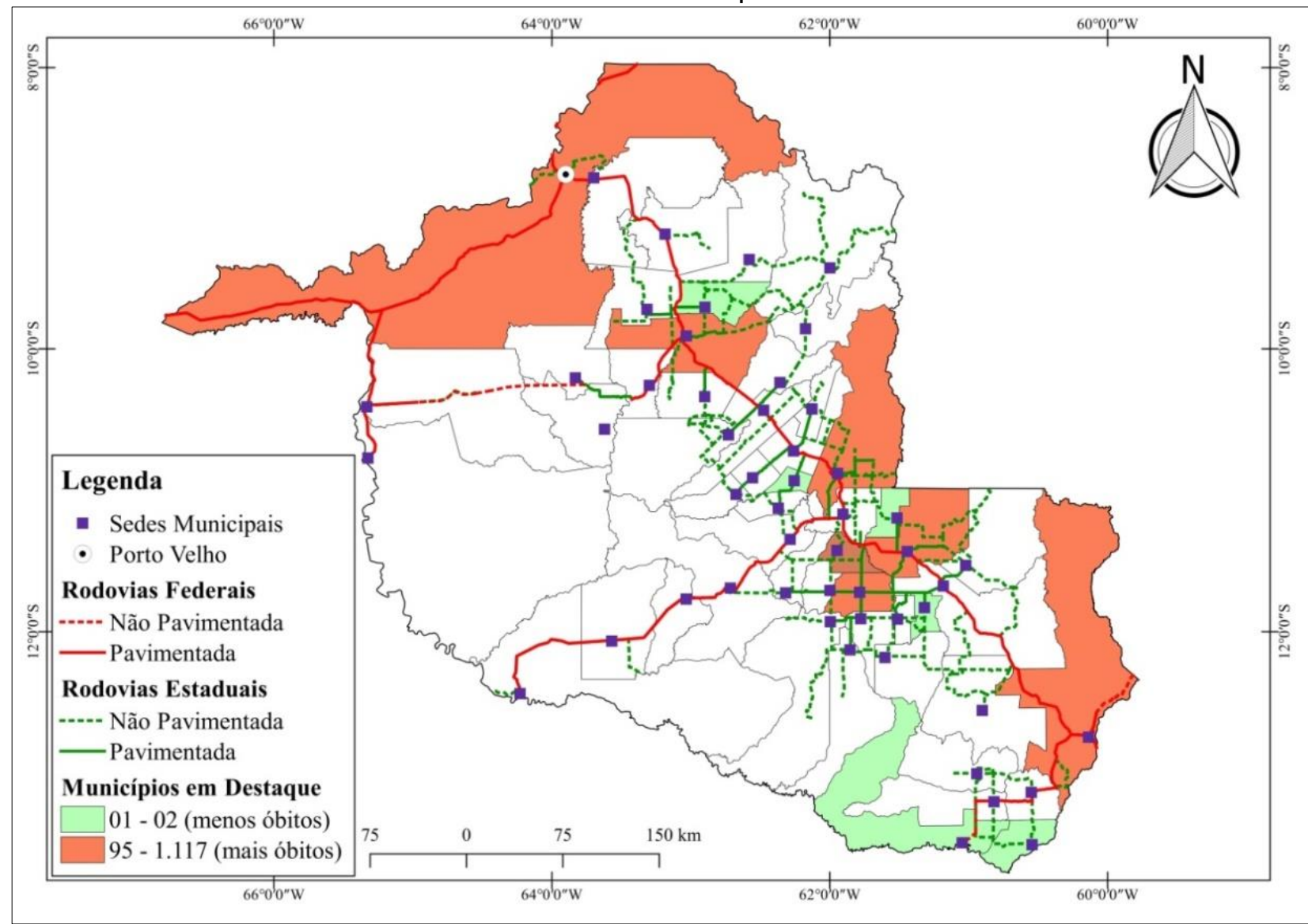

Fontes: SIM/SUS, 2009-2013; DNIT, 2013; IBGE, 2010

Dos municípios que apresentaram maior número de vítimas, cinco deles estão localizados às margens da principal rodovia do estado, a BR-364 (totalmente conectados) e Rolim de Moura no entroncamento de duas rodovias estaduais, a RO-479 e 010 (medianamente conectado). Já os municípios com o menor número de vítimas, quatro possuem acesso por rodovias estaduais e dois têm acesso precário: Cabixi e Pimenteiras do Oeste, ambos localizados no extremo sudoeste do estado.

Com uma distribuição da população, frota de veículos e de óbitos similar, os pontos dos diagramas agrupados, acompanhando a linha de tendência de crescimento e uma ordem quase perfeita da amostra de municípios, a principal conclusão que os resultados apontam é que: os municípios mais populosos e com maior frota de veículos são os que apresentaram maior número de óbitos por ATT. E estes estão localizados no eixo da BR364 ou próximos a ela; os municípios com menor população e menor frota de veículos registraram menor quantidade de óbitos e estão localizados nas rodovias estaduais ou estradas não pavimentadas. Levando-se em consideração esses aspectos, conclui-se que há uma forte correlação entre as variáveis analisadas nos municípios de Rondônia.

\section{PARÁ}

De acordo com o levantamento feito a partir da base cartográfica do DNIT (2013), cerca de cento e catorze municípios do estado têm acesso por meio do modo rodoviário, sendo: trinta e sete por rodovias federais, quarenta e nove por rodovias estaduais e vinte e 
oito por rodovias não pavimentadas. $E$ apenas vinte e nove não apresentam conexão rodoviária, situados na porção norte. O mosaico de mapas da figura 5 (A, B, C e D) destaca a relação de acessos aos municípios com a distribuição da população, frota de veículos e os óbitos por ATT no estado.

Figura 5 - Pará: Mosaico de mapas com as categorias de acesso (A), população (B), frota de veículos (C) e óbitos (D)

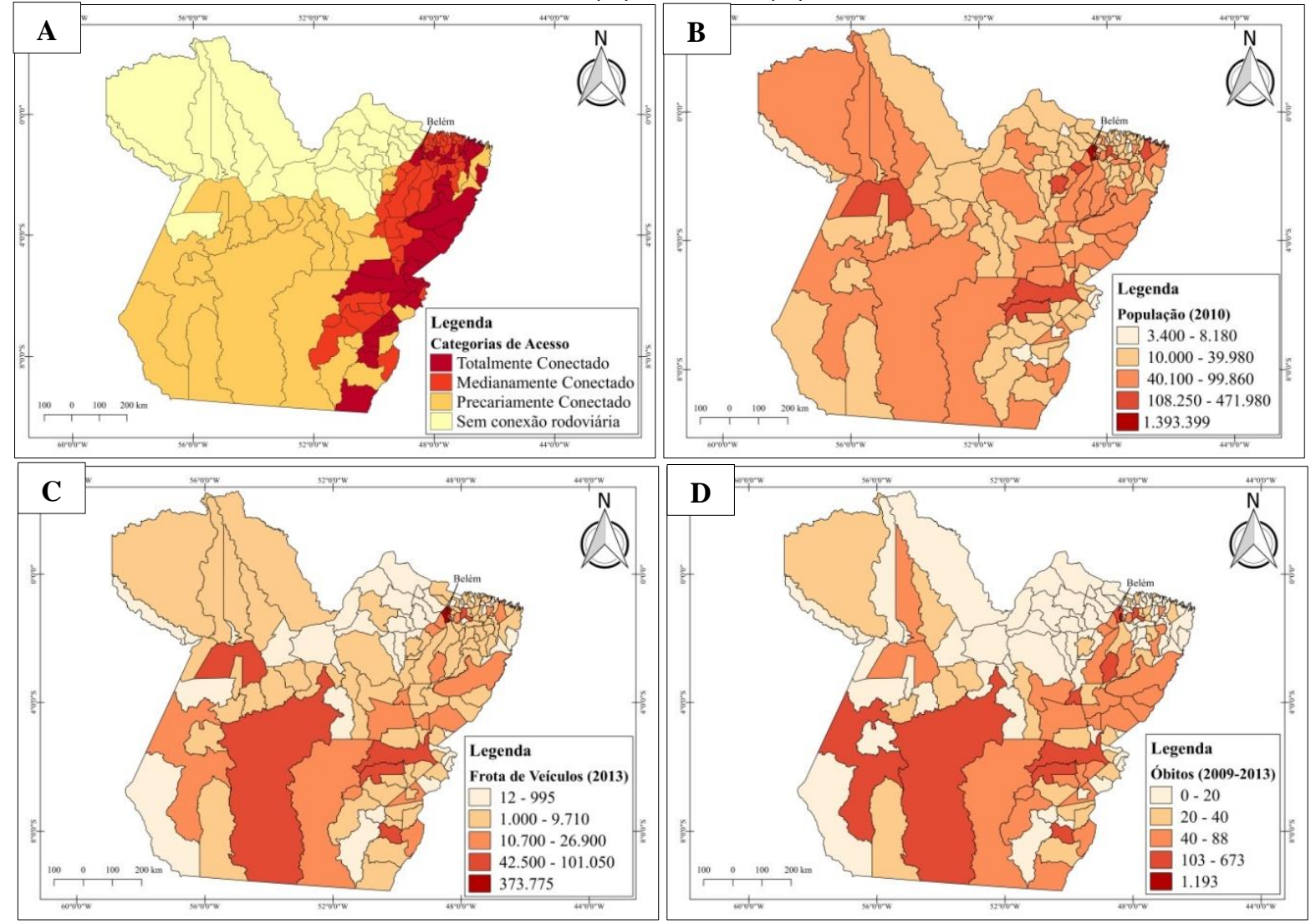

Fontes: DNIT,2013; IBGE,2010; DENATRAN, 2013; SIM/SUS, 2009-2013

Com mais de 7.5 milhões de habitantes, a maior parte dos municípios do Pará são populosos, principalmente aqueles localizados na borda leste, na região centro-sul, conforme aponta a figura $5 \mathrm{~A}$. Belém concentra 1.393 .399 de habitantes, cerca de 18,34\%. Ananindeua é a segunda maior população do estado, com mais de 471 mil habitantes. Além destes, destacam-se no mapa em tons mais escuros aqueles com mais de 100 mil habitantes, tais como: Marituba, Bragança, Cametá, Abaetetuba, Parauapebas, Castanhal, localizados ao leste, nordeste e próximos a Belém. Com mais de $3 \%$ da população, Marabá ao sul da capital e Santarém no oeste do estado, são também populosos, com mais de 200 mil habitantes. Já os municípios menos populosos são aqueles localizados na ilha do Marajó, e no sudeste, entre 10 a 30 mil habitantes. E são poucos aqueles com menos de 8 mil habitantes.

A figura 5 trata-se da distribuição da frota de veículos no estado. De acordo com o DENATRAN (2013), a frota de veículos do Pará era de aproximadamente 1.4 milhões. A capital do estado concentrava cerca de $26,16 \%$, com mais de 373 mil veículos. A segunda maior frota é de Ananindeua, localizado na região metropolitana de Belém, com 101.057 veículos. Muitos são os municípios com frota inferior a 10 mil veículos, situados principalmente ao nordeste, na região central e noroeste do estado. Aqueles ao norte, a 
oeste de Belém têm a menor frota do estado, tais como Chaves, com 12 veículos, Afuá, com 16 e Faro, na fronteira com o Amazonas, com 76 veículos.

De acordo com os dados do SIM/SUS, no período de 2009-2013, o Pará é o estado com maior número de vítimas por ATT, com 6.837 óbitos. É o único da AL que a capital, Belém, ocupa a segunda posição nos números de óbitos, com 673 mortes, conforme destaca a figura 5 D. É o município de Ananindeua, com 1.193 óbitos que ocupa a primeira posição do estado. Os municípios do nordeste e noroeste de Belém, cujas sedes têm maior influência dos rios, apresentam menos óbitos que aqueles do sul e leste do Pará, com conexão por rodovias. Em tons de laranja destacam-se: Castanhal, Tucuruí, Itaituba, Tailândia com mais de 100 óbitos, e Redenção, Parauapebas, e Altamira, com cerca de 250 óbitos. Doze municípios não apresentaram nenhuma vítima por ATT. Os diagramas de dispersão da figura 6 ( $A$ e $B$ ) esboçam a correlação das variáveis população e frota de veículos com os óbitos de cento e quarenta e três municípios do Pará, sem a capital, Belém.

Figura 6 - Pará: Diagramas de dispersão: (A) população municipal e (B) frota de veículos municipal; e óbitos por ATT

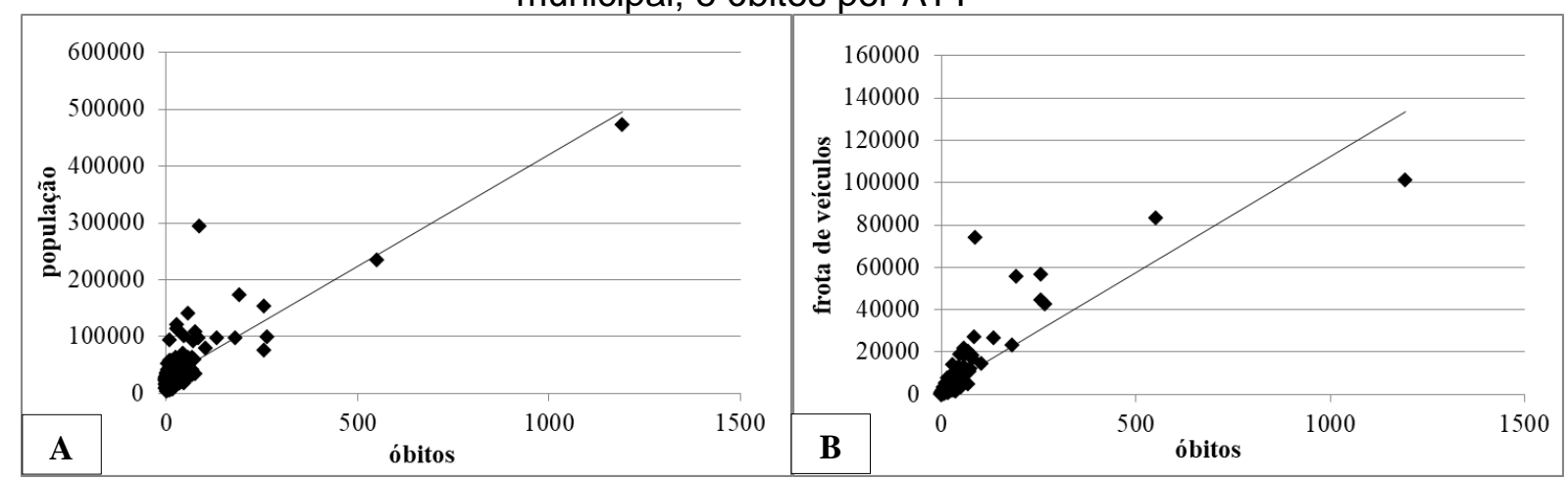

Fontes: SIM/SUS, 2009-2013; IBGE, 2010; DENATRAN, 2013

Ambos os gráficos apontam que existe uma grande diferença no número de vítimas entre os municípios do estado, a maior parte deles com menos de 200 óbitos, agrupados na base do gráfico e Ananindeua, com mais de 1.200 mortes por ATT, disperso em relação aos demais. Há municípios cuja população e a frota de veículos crescem, porém, o número de óbitos permanece menor que aqueles que apresentam menor quantitativo nestas variáveis. Dentre estes, o município de Santarém com uma população de aproximadamente 300 mil habitantes e uma frota de 300 mil veículos, apresentou menos óbitos que os municípios com menos de 60 mil veículos e uma população de 200 mil habitantes. Para melhor compreender a relação entre essas variáveis, a tabela 2 representa, em ordem crescente, quinze municípios do Pará que apresentaram mais óbitos de 2009 a 2013, e relacionados com a população e a frota de veículos municipal. 
Tabela 2 - Pará - Representação em ordem crescente dos municípios com menor e maior número de óbitos, comparados com a ordem da população e frota de veículos

\begin{tabular}{|c|c|c|c|c|c|c|}
\hline \multirow[b]{2}{*}{ Município } & \multicolumn{2}{|c|}{ Óbitos } & \multicolumn{2}{|c|}{ População } & \multicolumn{2}{|c|}{ Frota de Veículos } \\
\hline & Posição & Total & Posição & Total & Posição & Total \\
\hline Ananindeua & 10 & 1.193 & 2o & 471.980 & 2 o & 101.057 \\
\hline Belém & 20 & 673 & 10 & 1.393 .399 & 10 & 373.775 \\
\hline Marabá & 30 & 552 & 40 & 233.669 & 30 & 83.310 \\
\hline Altamira & 40 & 266 & 12 은 & 99.075 & 80 & 42.499 \\
\hline Parauapebas & 5은 & 257 & 60 & 153.908 & 5o & 56.322 \\
\hline Redenção & 60 & 257 & 190 & 75.556 & 70 & 44.524 \\
\hline Castanhal & 70 & 193 & 5은 & 173.149 & 60 & 55.699 \\
\hline Tucuruí & 80 & 182 & 15 은 & 97.128 & $11^{\circ}$ & 23.167 \\
\hline Itaituba & 9o & 135 & 140 & 97.493 & $10^{\circ}$ & 26.306 \\
\hline Tailândia & 10 은 & 103 & 18 은 & 79.297 & $18^{\circ}$ & 14.647 \\
\hline Santarém & 110 & 88 & 3 은 & 294.580 & 40 & 73.929 \\
\hline Paragominas & 12 o & 85 & 13 은 & 97.819 & 90 & 26.884 \\
\hline Marituba & 13 은 & 78 & 10 은 & 108.246 & $17 \stackrel{0}{2}$ & 16.648 \\
\hline Tucumã & $14 ㅇ$ & 78 & 59 은 & 33.690 & 16 & 18.101 \\
\hline Santa Izabel do Pará & $15 \circ$ & 75 & 240 & 59.466 & 22 음 & 12.060 \\
\hline
\end{tabular}

Nota-se muitas diferenças no que se refere a ordem dos dados, tanto na frota de veículos quanto à população. Nenhum dos municípios apresenta uma posição similar nas três variáveis, são apenas aproximadas, como é o caso de: Ananindeua, Belém, Marabá, Parauapebas e Castanhal. A maior diferença ordinal dos dados é observada nos municípios de Altamira, Santarém, Tucumã e Santa Izabel do Pará em ambas as variáveis. Dentre esses aspectos, é importante ressaltar: a) Ananindeua com uma diferença de mais de 200 mil veículos e população de 920 mil em relação a Belém, apresentou quase o dobro do número do número de óbitos que essa, com 1.193 e 673 vítimas em respectivamente; b) Altamira e Parauapebas, quarta e a quinta posição na geração de óbitos, com aproximadamente 250 vítimas, e apresentaram uma população de 140 a 200 mil habitantes e uma frota de 42 a 56 mil veículos respectivamente. Uma diferença de mais de 20.000 veículos que Santarém, que apresentou cerca de 88 óbitos, três vezes menor que as dos municípios citadas; c) Tucumã com 78 óbitos, 33 mil habitantes e 18.101 veículos registrou um número quase equivalente de vítimas que Santarém, com frota e população muito superior que o município de Tucumã; d) Ao relacionar Santarém ao município de Marabá, a terceira e a quarta maior população e frota de veículos do estado, verifica-se que estes têm números muito diferentes de óbitos, enquanto Santarém apresentou 88 óbitos, em Marabá, é seis vezes maior, com 556 vítimas.

A figura 7 destaca trinta municípios do Pará, com o menor e maior número de óbitos do estado, relacionados com tipo de acesso às sedes municipais. 
Figura 7 - Pará: Mapa com destaque dos municípios que geraram maior e menor número de

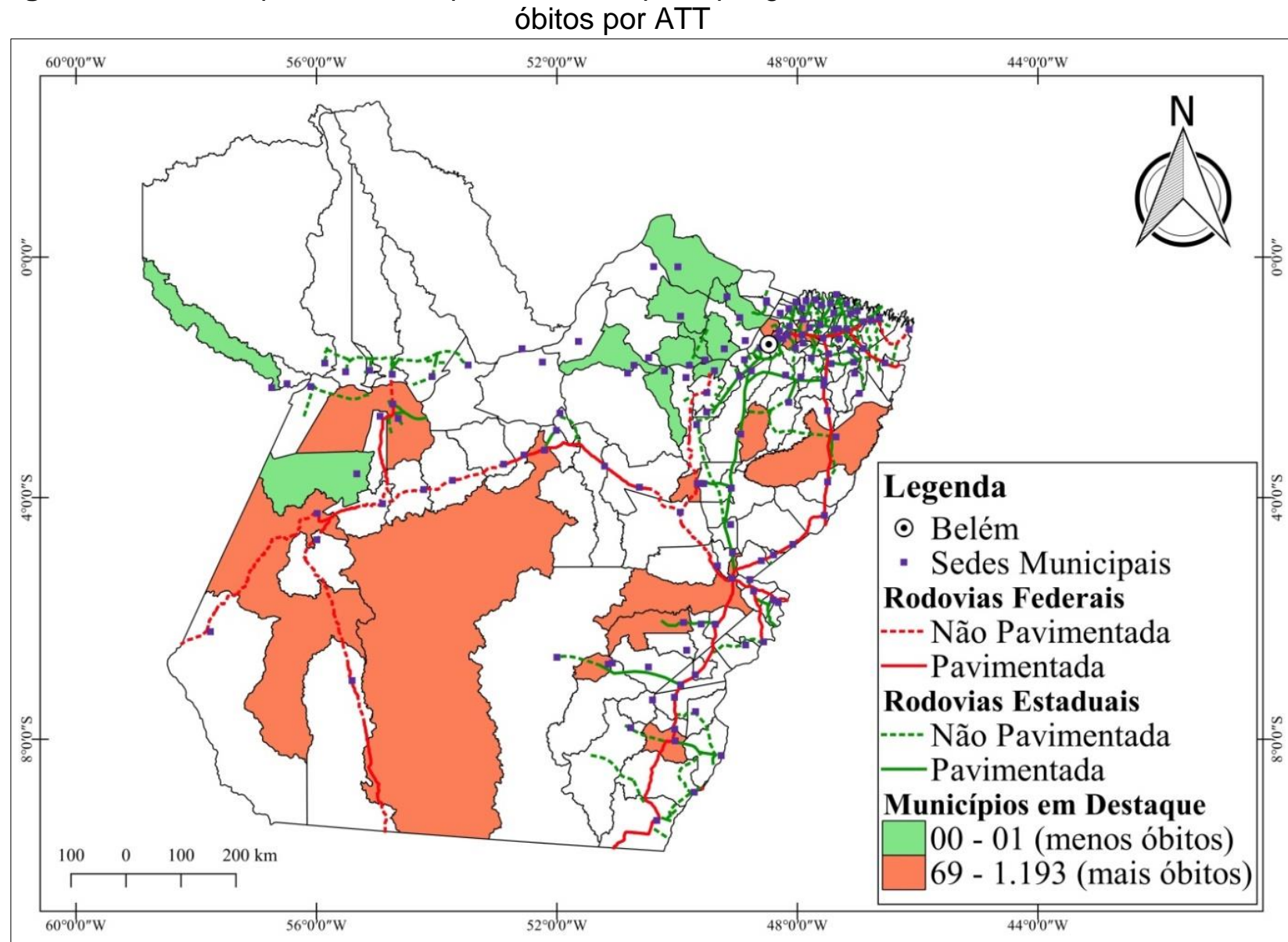

Fontes: DNIT, 2013; IBGE, 2010; DENATRAN, 2013; SIM/SUS, 2009-2013

O mapa destaca que os municípios com mais de 69 óbitos possuem algum tipo de conexão rodoviária, sejam elas federais ou estaduais. Em suma, sete deles são totalmente conectados, muitos pela BR-010 (Belém-Brasília), situados próximos a Belém, e outros na BR-158, três são medianamente conectados e cinco precariamente conectados. Muitos nas margens das BR-230, 163 e 422. Já aqueles com menor quantidade de vítimas, a maioria estão situados na margem de rios navegáveis da região, muitos deles na ilha do Marajó, ao total são onze sem conexão rodoviária, dois medianamente conectados, (na região nordeste, próximos ao litoral) e dois são precariamente conectados.

O Pará é o estado com maior número de vítimas por ATT da Amazônia Legal. Além da capital, muitos municípios contribuem para este dado, principalmente aqueles localizados na borda leste. Em virtude do que foi mencionado sobre as suas características populacionais, frota de veículos e óbitos, percebe-se que a população do estado é bem distribuída nos municípios, e muitos deles apresentam mais de 50.000 habitantes. Por outro lado, a frota de veículos tem uma distribuição mais irregular, sendo concentrada em alguns municípios. Assim sendo, a distribuição dos óbitos associa-se mais com aquela espacialidade da frota de veículos do que com a população. Na correlação das variáveis, observa-se que ela não é perfeita, ressaltadas nas tabelas e nos gráficos de dispersão. Isso significa que no estado há vários municípios com alta população e frota veículos, e com menor número de óbitos que aqueles quantitativos menores. 


\section{AMAZONAS}

A figura 8 A elaborada a partir da base do DNIT (2013) aponta que cerca de quarenta e oito municípios do Amazonas não possuem conexão rodoviária, sete são conectados por rodovias estaduais, cinco possuem acesso precário por rodovias não asfaltadas e apenas quatro são conectados por rodovias federais. O mosaico de mapas da figura 8 ( $A, B, C$ e D) destaca a relação de acesso às sedes municipais, com a distribuição da população, frota de veículos e os óbitos por ATT no estado.

Figura 8 - Amazonas: Mosaico de mapas com as categorias de acesso $(A)$, população $(B)$, frota de veículos $(C)$ e óbitos (D)

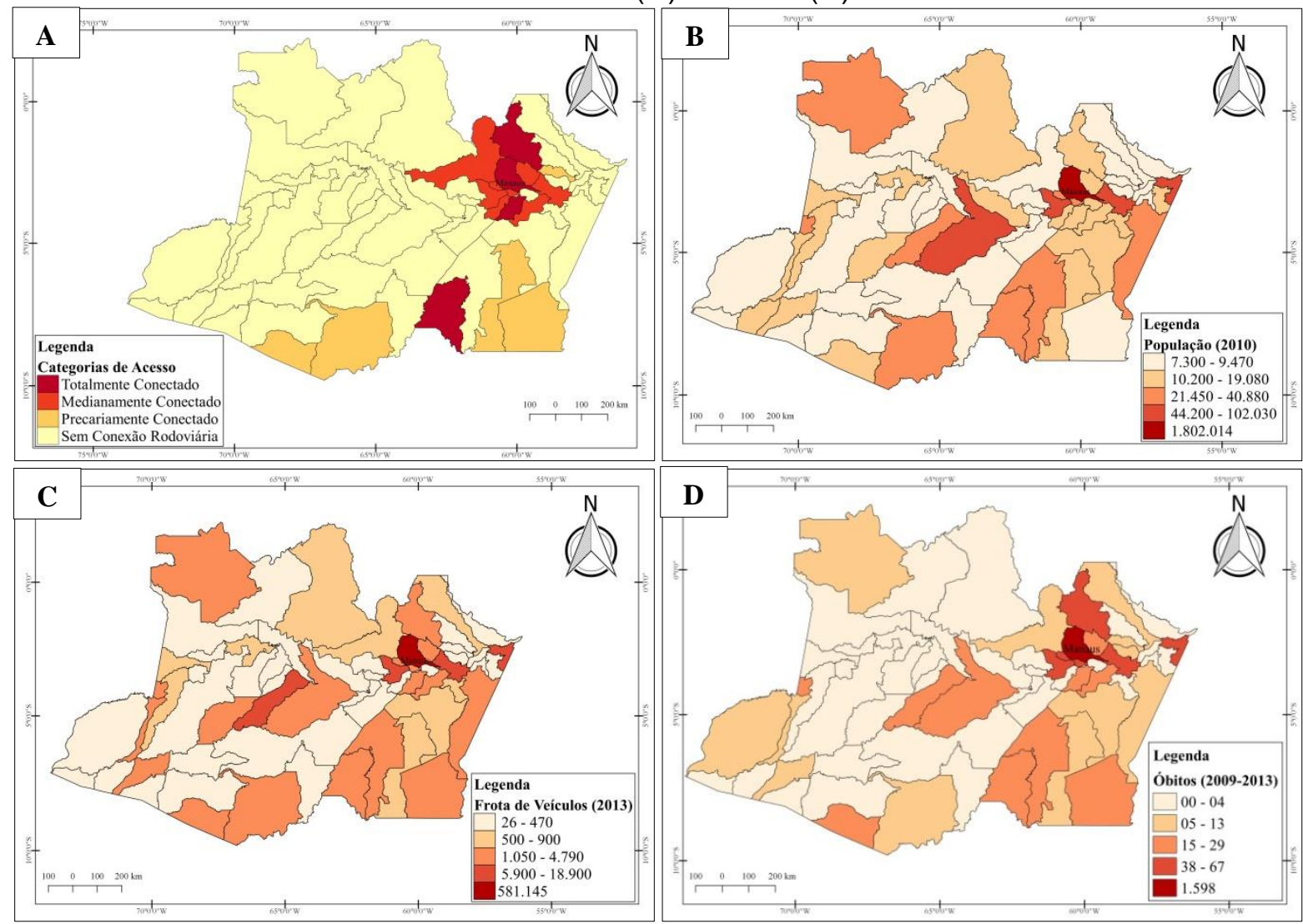

Fontes: DNIT, 2013; IBGE, 2010; DENATRAN, 2013; SIM/SUS, 2009-2013

De acordo com o IBGE (2010), a população do Amazonas era mais de 3,4 milhões de habitantes e cerca de 51,72\% está concentrada em Manaus, com aproximadamente 1,8 habitantes. Ao leste de Manaus, localizam-se os dois municípios mais populosos do Amazonas: Parintins e Itacoatiara com mais de 100.000 e 86.000 mil habitantes, respectivamente. $\mathrm{O}$ terceiro mais populoso é Manacapuru, com 85 mil habitantes, a sudoeste desta. O mapa ressalta, em tonalidades claras, que a maior parte dos municípios do Amazonas tem uma população inferior a 10 mil habitantes, principalmente aqueles do oeste e nordeste do estado. Em tons de laranja, sobressaem-se, em relação aos demais, os municípios de Coari e Tefé na região central, Tabatinga a oeste, no sudeste e sul Maués, Manicoré, Humaitá e Lábrea.

Em sua maioria, a frota de veículos no Amazonas concentra-se naqueles municípios que apresentaram maior contingente populacional, segundo destacado na figura $8 \mathrm{C}$. Assim como a população, Manaus também concentra a maior parte da frota do estado, reune $82,92 \%$, com mais 518 mil veículos. Parintins e Itacoatiara, com aproximadamente $2 \%$ ocupam a segunda e terceira posição, com mais 18 e 14 mil veículos. Por outro lado, há 
aqueles municípios que apresentam frota com menos de 1.000 veículos, com maior frequência no oeste e no nordeste do estado. Aqueles próximos a Manaus, no sul, sudeste e na região central têm a maior frota de veículos, dentre eles, destacam-se: Tefé e Coari com mais de 8 mil veículos, Tabatinga, Humaitá e Presidente Figueiredo com aproximadamente 5 mil veículos.

O mapa da figura 8 destaca que são alguns municípios da região Metropolitana que apresentaram o maior número de óbitos no período de 2009 a 2013. Dentre estes, destacam-se: Itacoatiara, Presidente Figueiredo e Manacapuru com cerca de 65 óbitos e a leste Parintins, com 38 vítimas. Com percentual de $70.80 \%$ dos óbitos, Manaus apresentou 1.598 vítimas de ATT no período, sendo o município com maior número de óbitos na AL. Em tom laranja, sobressaem-se os municípios do sudeste de Manaus, como Careiro e Autazes, ao sul do estado, Apuí, Manicoré, Humaitá e Boca do Acre. E na região central, Tefé e Coari. A maior parte dos municípios do leste apresentaram um baixo número de vítimas, sete deles não registraram nenhum óbito, como Anamã, Beruri, Ipixuna, Juruá, Maraã, Nhamundá e São Sebastião do Uatumã. Os diagramas de dispersão da figura 9 (A e B) trata-se da correlação das variáveis população e frota de veículos com os óbitos de 61 municípios do Amazonas, sem a capital, Manaus.

Figura 9 - Amazonas: Diagramas de dispersão: (A) população municipal e (B) frota de veículos municipal; e óbitos por ATT

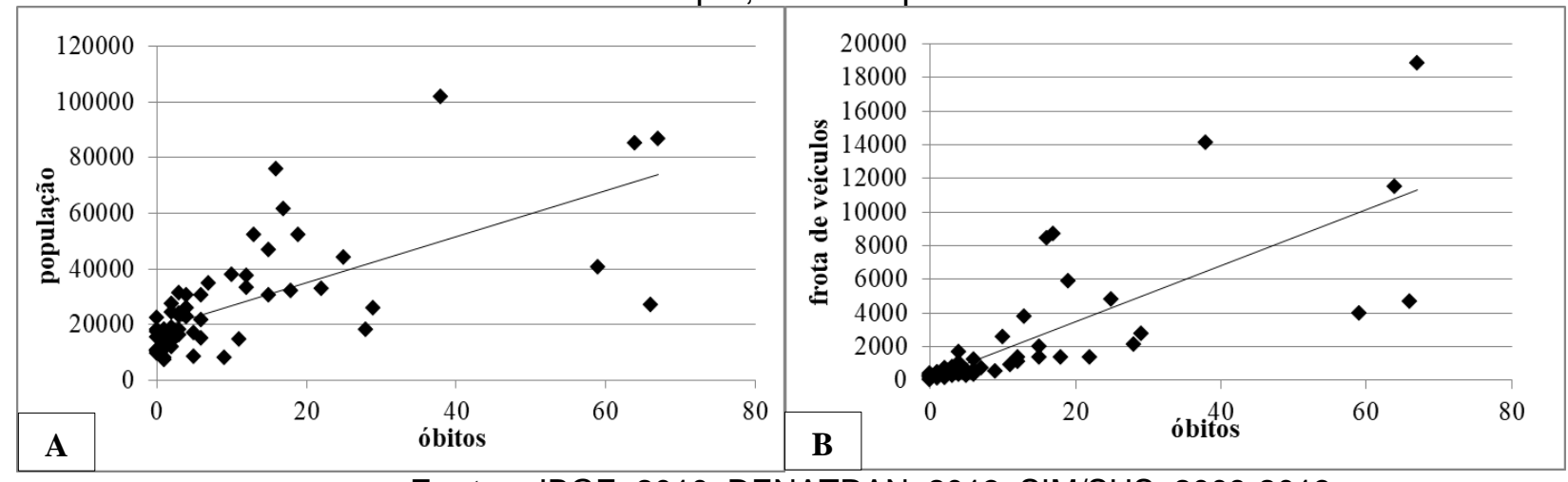

Fontes: IBGE, 2010; DENATRAN, 2013; SIM/SUS, 2009-2013

Os diagramas destacam o agrupamento na base, seguida de um espalhamento dos pontos ao longo de toda a linha de tendência, principalmente no gráfico A. Ou seja: há uma diferença entre a população, a frota de veículos com o número de vítimas apresentada pelos municípios, assim como muitas disparidades no total das variáveis nos municípios representados.

No gráfico $A$, os municípios com mais alta população, com é o caso de Coari, Tefé e Tabatinga, com mais de 40 mil habitantes, apresentaram menos óbitos que os municípios localizados na parte inferior da linha de tendência; o município de Parintins, situado na grade de 100 mil, apresentou menos vítimas que quatro municípios com menor população que este. Na parte inferior da reta de tendência, tanto no gráfico A como no B cresce o número de óbitos, porém em relação à população e à frota de veículos o aumento é mais modesto que aqueles da parte superior da reta. A tabela 3 representa, em ordem crescente, os sete municípios do Amazonas que apresentaram mais óbitos de 2009 a 2013, relacionados com a população e a frota de veículos municipal. 
Tabela 3 - Amazonas: Representação em ordem crescente dos municípios com maior número de óbitos, comparados com a população e frota de veículos.

\begin{tabular}{|c|c|c|c|c|c|c|}
\hline \multirow[b]{2}{*}{ Município } & \multicolumn{2}{|c|}{ Óbitos } & \multicolumn{2}{|c|}{ População } & \multicolumn{2}{|c|}{ Frota de Veículos } \\
\hline & Posicão & Total & Posicão & Total & Posicão & Total \\
\hline Manaus & $1 \underline{0}$ & 1.598 & $1^{0}$ & 1.802 .014 & $1^{\circ}$ & 581.145 \\
\hline Itacoatiara & $2^{\circ}$ & 67 & 3으 & 86.839 & $2^{\circ}$ & 18.876 \\
\hline Presidente Figueiredo & 3으 & 66 & $23^{\circ}$ & 27.175 & 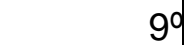 & 4.682 \\
\hline Manacapuru & $4 \stackrel{0}{-}$ & 64 & 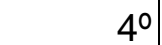 & 85.141 & $4 \stackrel{0}{-}$ & 11.499 \\
\hline Iranduba & $5^{\circ}$ & 59 & $11^{\circ}$ & 40.781 & $10^{\circ}$ & 3.958 \\
\hline Parintins & 6은 & 38 & $2^{\circ}$ & 102.033 & 30 & 14.135 \\
\hline Rio Preto da Eva & $7^{0} \underline{0}$ & 29 & $25^{\circ}$ & 25.719 & $12^{\circ}$ & 2.738 \\
\hline
\end{tabular}

Nota-se que, assim como Manaus, Manacapuru é o município que mais se assemelha pelo número de óbitos ser equivalente à ordem da população e da frota de veículos em relação aos demais do estado. A tabela também aponta que municípios com população e frota de veículos similares, apresentaram números diferenciados de óbitos, como é o caso de Parintins e Itacoatiara. Sendo Parintins, a segunda maior população e a terceira maior frota de veículos, mas registrou 38 óbitos, ocupando a sexta posição, o dobro menor que os óbitos apresentados por Itacoatiara, com 67 vítimas por ATT. É necessário atentar para os municípios de Presidente Figueiredo, com 66 óbitos e Iranduba com 59, que ocupam a terceira e a quinta posição no número de óbitos, por outro lado, estes possuem uma população de cerca de 27.175 e 40.881 e uma frota de 4.781 e 3.958 veículos respectivamente, números muito inferiores àquele apresentado por Itacoatiara, no entanto a quantidade de óbitos é muito aproximada. A figura 10 destaca a relação de catorze municípios que apresentaram mais e menos óbitos no Amazonas com as categorias de acesso às sedes municipais. 
Figura 10 - Amazonas: Mapa com o destaque dos municípios que geraram maior e menor número de óbitos por ATT

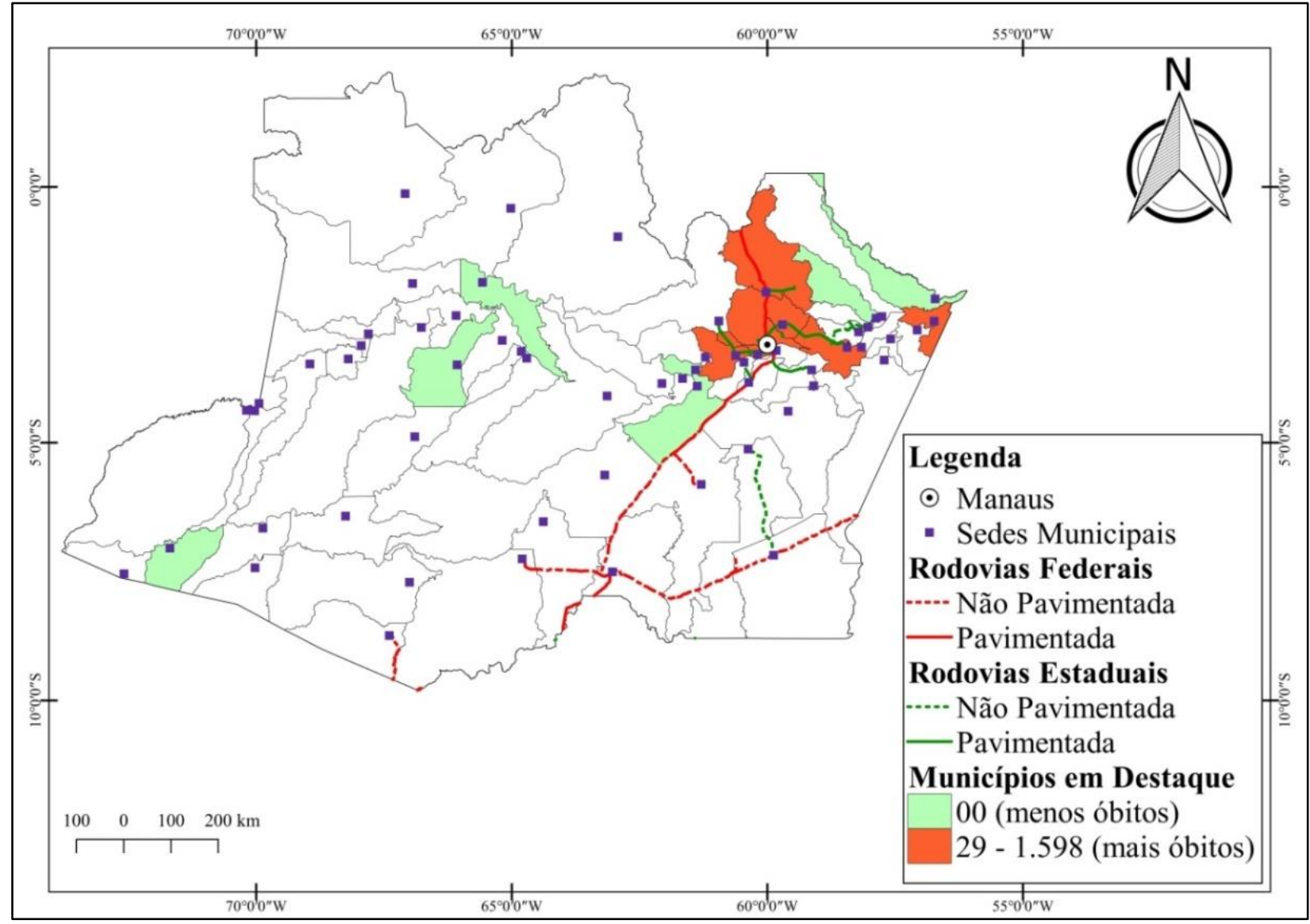

Fontes: SIM/SUS, 2009-2013; DNIT, 2013; IBGE, 2010

O mapa destaca que os municípios com mais óbitos são aqueles localizados próximos de Manaus, com acesso por meio de rodovias, exceto Parintins a leste, situado na margem do rio Amazonas. Dois deles são totalmente conectados e quatro medianamente conectados. Por outro lado, todos aqueles do grupo de menos óbitos não têm conexão rodoviária.

Dentre os estados da Amazônia Legal, o Amazonas é o que apresenta maior influência do transporte fluvial. Sua população tem uma distribuição bastante irregular, concentrada em poucos municípios, enquanto a maioria tem uma baixa concentração populacional. Este padrão espacial reflete-se na distribuição da frota de veículos e em alguns casos no número de óbitos do período estudado. Em razão dessa irregularidade da população e da frota de veículos, os diagramas de dispersão não nos permitem concluir uma correlação forte das variáveis analisadas. Por outro lado, as tabelas apontam algumas relações equivalentes nos quantitativos apresentados na amostra de municípios e deixam nítida a relação que se estabelece da influência rodoviária na geração de vítimas nos municípios, muito bem apresentado por Presidente Figueiredo, Rio Preto da Eva em relação a Parintins, em que os primeiros têm conexão via rodovia federal e estadual e Parintins por via fluvial. No entanto, a população e a frota de veículos de Parintins são superiores a apresentada por Presidente Figueiredo e Rio Preto da Eva. 


\section{CONSIDERAÇÕES FINAIS}

O aumento da taxa de motorização é apontado na literatura como uma das principais causas do crescimento dos óbitos por ATT. Reconhece-se que esse fator é importante, porém é necessário avaliar as realidades que caracterizam cada contexto, seja ele regional ou local. Sabe-se que a Amazônia Legal apresenta uma configuração geográfica com padrões de cidades cuja gênese ocorreu por meio dos rios navegáveis, em contrapartida as mais recentes cidades foram formadas à margem de rodoviárias. Essas diferenças de acesso às sedes municipais são fatores que devem ser considerados para entender a distribuição das ocorrências de óbitos por ATT na região.

Tendo em vista aos aspectos observados na análise dos dados, a distribuição da população, da frota de veículos e dos óbitos nos respectivos estados, considerando a escala municipal, verificou-se que há uma configuração geográfica associada aos eixos rodoviários.

O estado de Rondônia apresentou alta correlação entre todas as variáveis analisadas, ou seja: os municípios com acesso rodoviário federal apresentam maior concentração da população e da frota de veículos e registraram maior quantidade de óbitos por ATT. Estado este que possui como principal modo de transporte o rodoviário.

Já o Pará e o Amazonas apresentam influência tanto do transporte fluvial quanto do rodoviário e apontam que o padrão de distribuição da população é definido somente pelos eixos rodoviários federais, pois os municípios situados à margem de rios também apresentam uma população similar ou maior que os municípios situados nos eixos rodoviários. No entanto, em ambos os estados, o padrão de distribuição dos óbitos está mais relacionado com a distribuição da frota de veículos e pelo acesso rodoviário do que com a população. No Amazonas, por exemplo: o município de Parintins, com acesso apenas fluvial, apresentou menos óbitos que Presidente Figueiredo, menor população e frota que aquele, porém situado na margem de uma rodovia federal, a BR-174; Rio Preto da Eva também aponta um número de óbitos maior que os municípios de Tefé e Coari, com maior população e frota de veículos, situados à margem de rios navegáveis. No Pará, o município de Santarém, com maior população e frota de veículos apresentou menos óbitos que Marabá e Altamira. Apesar de Santarém ser conectado por rodovia, a maior parte do trecho não se encontra pavimentado, isso implica na menor circulação de veículos (e/ou velocidades mais baixas para circulação).

Os resultados apontam ainda que há perfis diferenciados de munícipios, de acordo com a geração de vítimas: 1) Municípios com acesso apenas fluvial apresentam baixa geração de óbitos por ATT; 2) Municípios com maior quantidade de óbitos por ATT estão localizados às margens de rodovias federais, seguida das estaduais. No quesito, correlação de dados, conclui-se: 1) Municípios que guardam alta correlação entre as variáveis (tipo de acesso, população, frota de veículos e óbitos); 2) Municípios com baixa população e frota de veículos e maior registro de óbitos que outros com maior quantitativo nessas variáveis; 3) Municípios em que a correlação dos óbitos é maior com a população do que com a frota de veículos; 4) Municípios em que a correlação é maior com a frota de veículos do que com a população.

Em vista dos argumentos apresentados, constatou-se que nestes estados, tomados como amostra para uma análise da Amazônia Legal, aponta que há forte correlação entre a população, a frota de veículos com os óbitos causados por ATT. Todavia, essa relação pode ser influenciada pela presença de rodovias com acesso aos municípios e pela sua importância territorial e sua infraestrutura. Nesse sentido, os resultados confirmam a hipótese levantada neste artigo que os municípios com acesso por rodovias (asfaltadas e 
não asfaltadas) possuem maior quantidade de veículos por habitante e apresentam maior quantidade de óbitos causados por acidentes de transporte terrestres que aqueles com acesso apenas por via fluvial.

Todavia, alguns aspectos devem ser considerados como justificativas desses resultados, tais como: a) as rodovias, principalmente as federais, apresentam grande circulação de pessoas e veículos motorizados; b) elas constituem-se como importantes eixos de ocupação, possibilitando um crescimento mais acelerado da população e da frota de veículos que os municípios acessados apenas por meio dos rios; c) há uma maior taxa de motorização das cidades rodoviárias, já que são os principais meios de deslocamentos intraurbano, intermunicipal até mesmo interestadual. Diferente das cidades fluviais, que os veículos são apenas meios de deslocamentos intramunicipal e urbano, ficando a navegação responsável pelos demais tipos de deslocamentos.

Em relação aos dados do SIM/SUS trabalhados nessa dissertação e as demais fontes de levantamentos de óbitos por acidentes de transporte no Brasil, estes mostram-se ineficientes para trabalhar com óbitos por locais de ocorrência, impossibilitando analisá-los por trechos de rodovias, áreas urbanas e rurais.

\section{REFERÊNCIAS}

ANDRADE, S. M.; SOARES, D. A.; BRAGA, G. P.; MOREIRA, J. H.; BOTELHO, F. M. N. Comportamentos de risco para acidentes de trânsito: um inquérito entre estudantes de medicina na região sul do Brasil. Rev. Assoc. Med. Bras., v. 49, n. 4, p. 439-44, 2003.

BECKER, B. Undoing myths: the Amazon, an urbanized forest. In: CLÜSENER-GODT, M.; SACHS, Ignacy (Eds.). Brazilian perspectives on sustainable development for the Amazon region. Paris: UNESCO, p.53-89, 1995 (Man and Biosphere Series, 15).

BECKER, B. K. Geopolítica da Amazônia. Estudos Avançados [online], v. 19, n. 53, p. 71-86, 2005.

BROWDER, J.; GODFREY, B. Rainforest cities: urbanization, development, and globalization of the Brazilian Amazon. New York: Columbia University Press, 1997.

CARDOSO, G.; GOLDNER, L. G. Desenvolvimento e aplicação de modelos para previsão de acidentes de trânsito. Transportes, v. XV, p. 43-51, dezembro, 2007.

CASTRO, Edna (Org.). Cidades na floresta. São Paulo: Annablume; Belém: NAEA-UFPA, 2008.

DA MATTA, R.; VASCONCELLOS, J. G. M.; PANDOLFI, R. Fé em Deus e pé na tábua: ou como e por que o trânsito enlouquece no Brasil. Rio de Janeiro: Rocco, 2010.

DATASUS. Departamento de Informações do Sistema Único de Saúde. Sistema de Informações sobre Mortalidade - SIM (2001-2009). Disponível em: $<$ http://www2.datasus.gov.br/DATASUS/index.php?area=0205\&id=6937/>. Acesso em: 02 nov. 2016.

DENATRAN, Departamento Nacional de Trânsito. Frota de Veículos do RENAVAM (2001-2015). Disponível em: <http://www.denatran.gov.br/estatistica/237-frota-veiculos> Acesso em: 07 jun. 2017. 
DNIT, Departamento Nacional de Infraestrutura de Transportes. V Geo, Visualizador de Informações Geográficas. Mapa Multimodal da Amazônia Legal (2013). Disponível em: $<$ http://servicos.dnit.gov.br/vgeo/>. Acesso em: 10 jan. 2017.

FERRAZ, C.; RAIA JUNIOR, A.; BEZERRA, B. Segurança no Trânsito. São Carlos: NEST, 2008.

IBGE. Instituto Brasileiro de Geografia e Estatística. Censo Demográfico 2010: Características Gerais da População. Resultados da Amostra Amazônia Legal. Disponível em: <http://www.ibge.gov.br/home/estatistica/populacao/cnso2000/default_populacao.shtm> Acesso em 05 de junho de 2017.

MORAIS NETO, O. L. et al. Mortalidade por acidentes de transporte terrestre no Brasil na última década: tendência e aglomerados de risco. Ciênc. Saúde Coletiva, Rio de Janeiro, v. 17, n. 9, p. 601-612, set. 2012.

MORTARIE, R.; EUZÉBIO, G. L. O custo do caos. Revista Desafios do Desenvolvimento. Instituto de Pesquisas Econômica Aplicada, Brasília, ano 6, ed. 53, ago. 2009.

NASCIMENTO, J. A. S.; SILVA, J. K. T. Amazônia: Uma Abordagem Geográfica da Dinâmica Populacional Recente. Justiça Ambiental, ano 2, n. 3, abr. 2007.

SAWYER, D. Urbanização da fronteira agrícola no Brasil. In: LAVINAS, L. (Ed.). Urbanização da fronteira. Rio de Janeiro: Publipur, Universidade Federal do Rio de Janeiro, 1987, p.43-57.

TRINDADE JUNIOR, R. E.; NASSI, C. D. A miséria como causa dos acidentes de trânsito no Brasil, 2005. Disponível em: http://www.perkons.com.br/pt/estudos-e-pesquisas-detalhes/51/amiseria-como-causa-dos-acidentes-de-transito-no-brasil. Acesso em: 07 jun. 2017.

VASCONCELLOS, E. A. Mobilidade urbana e cidadania. SENAC, Rio de Janeiro, RJ, 2012.

WILDE, G. J. S. O limite aceitável do risco: uma nova psicologia de segurança e de saúde. Tradução Reinier J. A. Rozestraten. São Paulo: Casa do Psicólogo, 2005. 